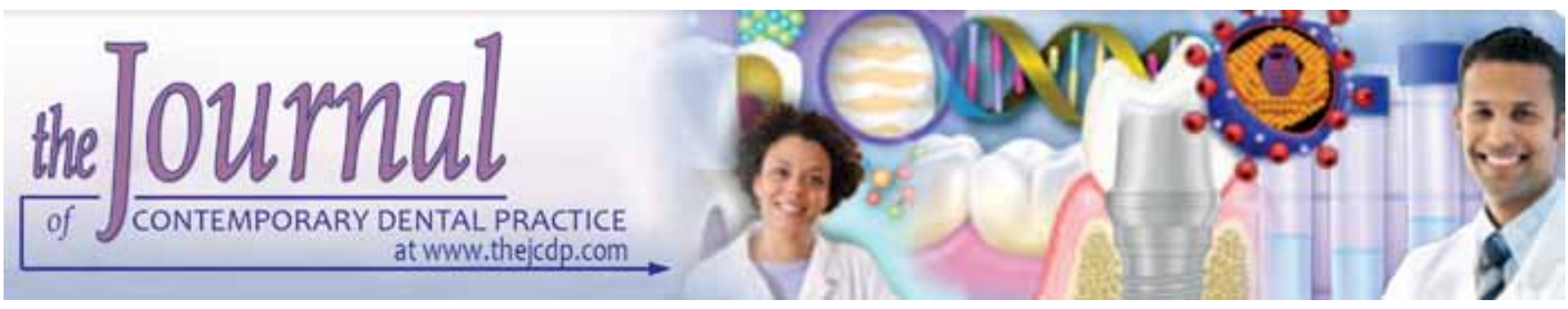

\title{
Effectiveness of Desensitizing Agents in relieving the Pre- and Postcementation Sensitivity for Full Coverage Restorations: A Clinical Evaluation
}

\author{
Naveen Gupta, Upendra Natha Reddy, P Leela Vasundhar, K Sita Ramarao, KVV Pratap Varma, V Vinod
}

\begin{abstract}
Patients frequently report sensitivity of prepared abutment teeth during the temporization period and after the final cementation of full coverage restoration.

Purpose of this clinical investigation was to evaluate the effectiveness of desensitizing agents in reducing the pre- and postcementation sensitivity for full coverage restorations and to compare the relative efficacy of three in office applied desensitizing agents in relieving the postcementation sensitivity with the use of glass ionomer luting cement.
\end{abstract}

Materials and methods: This study consisted of 30 patients requiring either full coverage restoration or 3 unit fixed partial denture. Total of 40 restorations $(n=40)$ were made and were randomly assigned into four groups comprising 10 restoration $(n=10)$ in each group. Group $C$ control where no desensitizer application was done, group BB applied with BisBlock dentin desensitizer (Bisco Inc.), group ST applied with Systemp desensitizer (Ivoclar Vivadent), group GC applied with GC Tooth Mousse desensitizer (GC Asia). Desensitizer application was done immediately after the tooth preparation. Sensitivity of the tested abutment was determined by the patient response to cold, hot and bite stimuli and were recorded on visual analog scale (VAS). Sensitivity level scores was evaluated at 4 time intervals, i.e. 1 week after desensitizer application at baseline precementation appointment and others at 5 minutes, 1 day and 1 week postcementation appointment. VAS score data was statistically analyzed using one-way ANOVA followed by post hoc Tukey's test.

Results: BisBlock and GC Tooth Mousse desensitizer resulted in statistically significant $(p<0.01)$ reduction in postcementation sensitivity of glass ionomer cement in comparison to Systemp desensitizer at 5 minutes, 1 week postcementation time interval with no statistical difference was seen between all desensitizer groups at 1 day postcementation. Application of BisBlock and GC Tooth Mousse desensitizer resulted in highly significant $(p<0.01)$ reduction in sensitivity level at the end of 1 week.

Clinical significance: Desensitizer's application on the prepared abutment teeth is considerably effective in relieving both pre- and postcementation sensitivity for full coverage restoration over the short duration of time. Immediate reduction in postoperative sensitivity relatively in a short time period may be beneficial in terms of patient's comfort. Nonetheless, multicenter long-term clinical trials should be conducted to confirm the results.

Conclusion: Efficacy of BisBlock and GC Tooth Mousse desensitizer was more in relieving the postcementation sensitivity of glass ionomer cement at various time intervals in comparison to Systemp desensitizer. In conclusion, application of desensitizers was beneficial to reduce the pre- and postcementation abutment sensitivity.

Keywords: Postcementation sensitivity, Dentin hypersensitivity, Dentin desensitizers, Abutment sensitivity.

How to cite this article: Gupta N, Reddy UN, Vasundhar PL, Ramarao KS, Varma KVVP, Vinod V. Effectiveness of Desensitizing Agents in relieving the Pre- and Postcementation Sensitivity for Full Coverage Restorations: A Clinical Evaluation. J Contemp Dent Pract 2013;14(5):858-865.

Source of support: Nil

Conflict of interest: None declared

\section{INTRODUCTION}

Prosthodontic procedures required for the fabrication of fixed partial denture on vital tooth have the potential to induce postoperative discomfort, dentinal hypersensitivity and subsequent pulpal irritation. Postcementation sensitivity rates have varied widely in clinical studies ranging from a low of $3 \%$ to a high of $34 \% .{ }^{1,2}$ Since the introduction of glass ionomer material as a luting medium for fixed restoration there has been considerable speculation regarding potential postcementation sensitivity. ${ }^{3,4}$ Number of possible causes that can develop abutment tooth sensitivity following tooth preparation and cementation have been suggested including aggressive tooth preparation, poor provisional restorations, 
bacterial leakage and contamination, desiccation of the preparation prior to cementation, ${ }^{5}$ removal of the protective smear layer and in vivo dissolution of the luting agents at the margin of restorations. ${ }^{6}$ To reduce the risk of vital abutment sensitivity an alternative approach proposed is the concept of sealing exposed dentin with desensitizing agents following tooth preparation and before cementation of restoration. ${ }^{7,8}$ Clinical efficacy of desensitizing agents in reducing the dentin sensitivity has been reported when applied on teeth prepared to receive complete cast restoration. ${ }^{9-11}$

The present study was conducted in the Department of Prosthodontics including Crown and Bridge and Implantology at College of Dental Sciences, Davangere.

The patients were accepted for the study on the basis of the following inclusion criteria. ${ }^{9}$

\section{Inclusion Criteria}

Individuals in generally good health.

1. Each patient had minimum of two teeth in need of complete coverage crown utilized as abutment teeth (missing 1st molar, unilateral or bilateral).

2. Teeth to be investigated displayed a vital pulp, confirmed by sensitivity response to electric pulp test.
3. Teeth radiographically demonstrated normal apical periodontal ligament space.

4. Previous restorations if present involve less than $50 \%$ of the coronal tooth surface.

5. Teeth had no previous history of hypersensitivity to thermal or other irritation.

\section{MATERIALS AND METHODS}

Thirty patients requiring 3 unit fixed partial denture or full coverage restorations on the maxillary or mandibular posterior teeth were selected for the study. The study was design to have a total of 40 restorations $(n=40)$. Prepared abutment were randomly assigned into four groups comprising 10 restoration in each group $(n=10)($ Fig. 1$)$.

1. Group C: Control-no desensitizer application was done.

2. Group BB: BisBlock dentin desensitizer (Bisco Inc, Schaumburg, USA) was applied.

3. Group ST: Systemp desensitizer (Ivoclar Vivadent AG, Schaan, Liechtenstein) was applied.

4. Group GC: GC Tooth Mousse desensitizer (GC-Asia dental Ptd. Ltd., Singapore) was applied.

5. Components of each desensitizing agents are presented in Table 1.
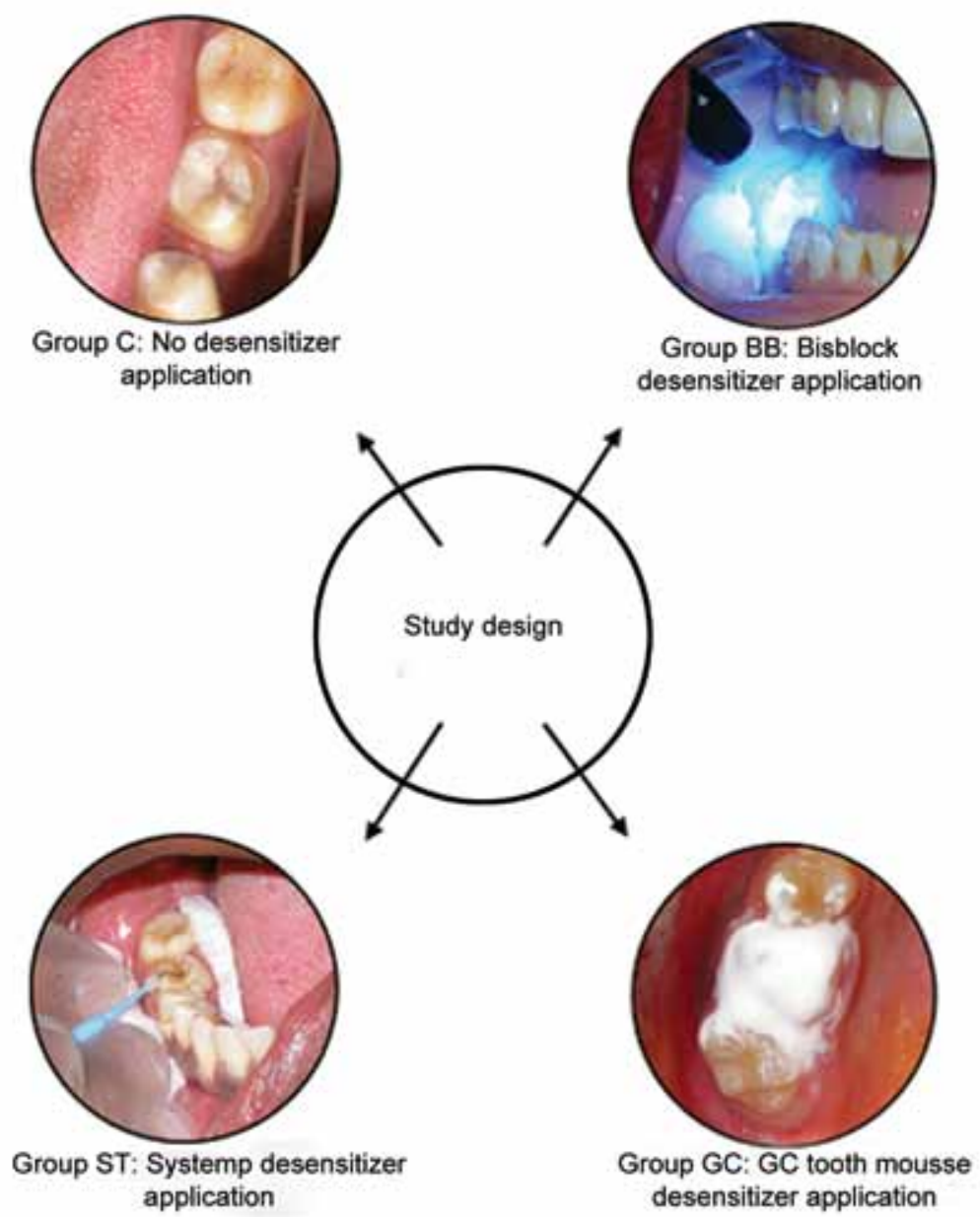

Fig 1. Study design with each group comprising of 40 restorations $(n=40)$ 


\begin{tabular}{|c|c|c|c|}
\hline $\begin{array}{l}\text { Dentin desensitizing } \\
\text { agents (DDAS) }\end{array}$ & Tubule occlusion & Active components & Manufacturer \\
\hline Bisblock & Salt (oxalate) & Oxalate dentin desensitizer & $\begin{array}{l}\text { Bisco Inc. Schaumburg, } \\
\text { USA }\end{array}$ \\
\hline Systemp & Glutaraldehyde & $\begin{array}{l}\text { Polyethylene glycol dimethacrylate glutaraldehyde } \\
\text { acqueous solution }\end{array}$ & $\begin{array}{l}\text { Ivoclar vivadent AG, } \\
\text { Schaan Liechtenstein }\end{array}$ \\
\hline GC tooth mousse & $\begin{array}{l}\text { Salt (calcium, and } \\
\text { phosphate) }\end{array}$ & $\begin{array}{l}\text { Pure water, glycerol CPP-ACP*, D-sorbitol, silicon } \\
\text { dioxide, CMC-Na, propyelene glycol, titanium } \\
\text { dioxide, xylitol, phosphoric acid, guar gum, zinc } \\
\text { oxide, sodium saccharin, ethyl p-hydroxybenzoate, } \\
\text { magnesium oxide, butyl-p-hydroxybenzoate, } \\
\text { propyl-p-hydroxybenzoate }\end{array}$ & $\begin{array}{l}\text { GC-Asia dental Pte. Ltd., } \\
\text { Singapore }\end{array}$ \\
\hline
\end{tabular}

6. In desensitizer groups respective desensitizer application was done following the manufacture directions immediately after tooth preparation before final impressions were made.

7. Single blind study was designed where patients were blinded to whether they were in one of the desensitizer group or control group. The same operator performed all treatments and evaluation for the study.

\section{METHODS EMPLOYED}

\section{Clinical Procedures}

Tooth preparation procedure: Teeth were prepared for complete coverage restorations according to standard prosthodontic principles using high speed handpiece, diamond instruments and copious water-coolant spray to minimize frictional heat and damage to the pulpal tissue.

Temporization procedure: Provisional restorations were made using Protemp TM II (3M ESPE, Germany), by direct method using polyvinyl siloxane putty (ExpressTM STD, 3M ESPE) matrix. After this, application of respective dentin desensitizer was done on prepared abutment teeth.

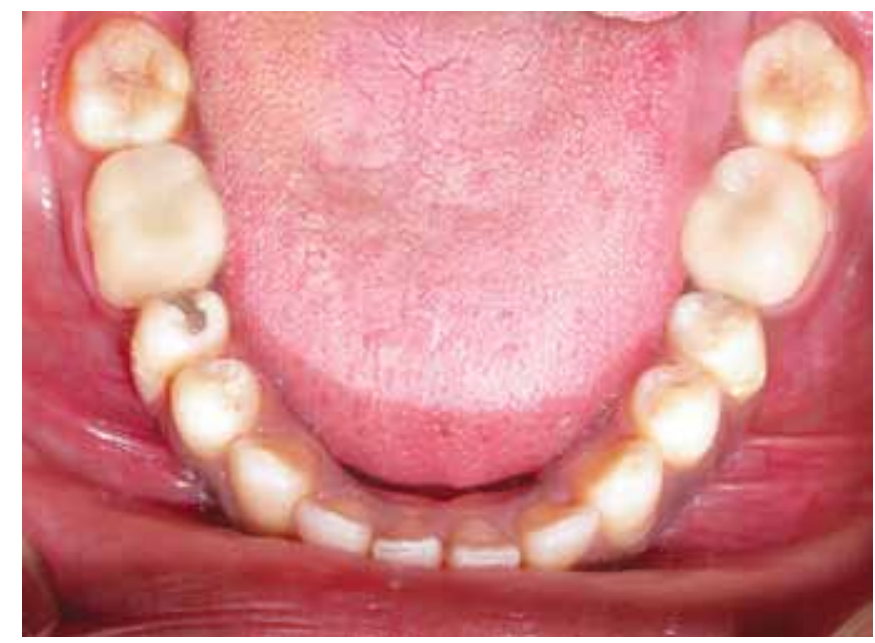

Fig 2. Provisional restorations were cemented with noneugenol provisional cement Tempbond NE (Rely $\mathrm{X}^{\mathrm{TM}} \mathrm{Temp}^{\mathrm{NE}}$, 3M ESPE, Germany)
After making the final impression, fabricated provisional restorations were cemented with noneugenol provisional cement Tempbond NE (Rely XTM TempNE, 3M ESPE, Germany) (Fig. 2).

Final cementation of restoration: After 1 week, cementation of final restoration was done with glass ionomer luting cement (GC Fuji-1, GC Corporation, Japan) mixed in accordance with the manufacturer's instructions. Excess cement was removed from the margins of the restoration.

\section{Patient Evaluation Procedures}

Evaluation of precementation sensitivity level: One week after desensitizer application, evaluation of precementation sensitivity level of the prepared teeth which was considered as baseline sensitivity level was done by removing the provisional restorations.

Procedure for evaluation: Subjective evaluation of pain produced by cold stimulus was done for checking precementation sensitivity. Polyvinyl siloxane putty matrix with an circular occlusal opening was used as a stent to provide a small reservoir surrounding the test tooth and cold

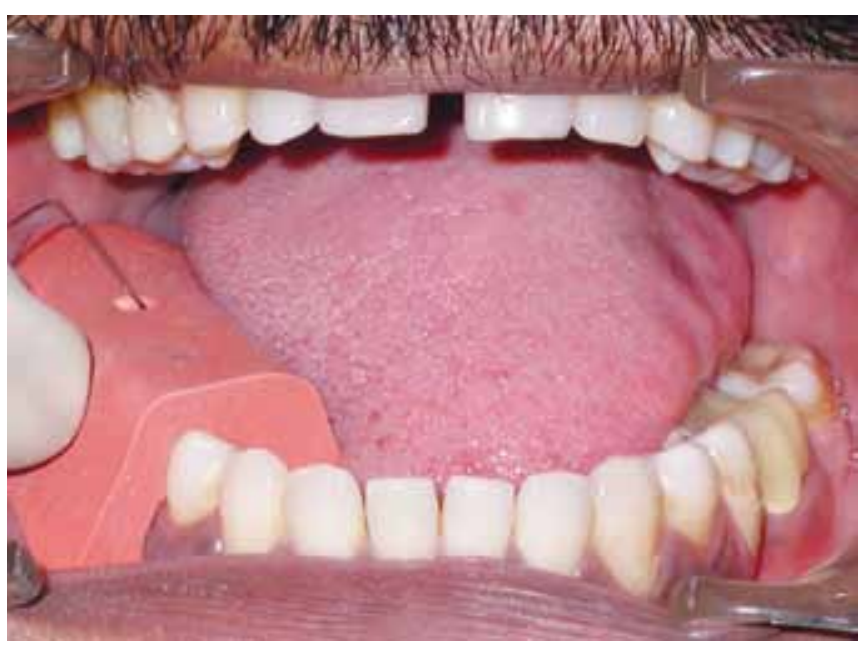

Fig 3. Cold water stimulus applied to the abutment tooth through a disposable plastic syringe with 22 gauge needle 
Effectiveness of Desensitizing Agents in relieving the Pre- and Postcementation Sensitivity for Full Coverage Restorations

\begin{tabular}{|c|c|c|c|c|c|c|}
\hline Time & $\begin{array}{l}\text { Group C } \\
\text { (1) }\end{array}$ & $\begin{array}{l}\text { Group BB } \\
\text { (2) }\end{array}$ & $\begin{array}{l}\text { Group ST } \\
\text { (3) }\end{array}$ & $\begin{array}{l}\text { Group GC } \\
\text { (4) }\end{array}$ & $\begin{array}{l}\text { ANOVA } \\
F^{\star} P\end{array}$ & $\begin{array}{l}\text { Sig. diff. between } \\
\text { groups }\end{array}$ \\
\hline \multirow[t]{3}{*}{ Precementation } & $5.1 \pm 2.5$ & $1.8 \pm 1.2$ & $4.3 \pm 1.8$ & $2.8 \pm 2.1$ & $5.71<0.01, \mathrm{~S}$ & 1 vs $2 \quad p<0.01$ \\
\hline & & & & & & 2 vs $3 \quad \mathrm{p}<0.01$ \\
\hline & & & & & & $\mathrm{BB}<\mathrm{GC}<\mathrm{ST}<\mathrm{C}$ \\
\hline \multirow[t]{4}{*}{5 mins postcementation } & $5.0 \pm 1.6$ & $1.1 \pm 0.7$ & $3.4 \pm 1.6$ & $1.3 \pm 1.9$ & $\begin{array}{l}14.8<0.001 \\
\mathrm{HS}\end{array}$ & $1-2,4 \quad p<0.001$ \\
\hline & & & & & & $p<0.01$ \\
\hline & & & & & & $p<0.05$ \\
\hline & & & & & & $\mathrm{BB}<\mathrm{GC}<\mathrm{ST}<\mathrm{C}$ \\
\hline \multirow[t]{2}{*}{ 1day postcementation } & $2.9 \pm 1.4$ & $0.3 \pm 0.7$ & $1.9 \pm 1.7$ & $1.3 \pm 1.9$ & $5.34<0.01, S$ & $p<0.01$ \\
\hline & & & & & & $\mathrm{BB}<\mathrm{GC}<\mathrm{ST}<\mathrm{C}$ \\
\hline \multirow[t]{2}{*}{1 week postcementation } & $1.0 \pm 1.2$ & 0.0 & $0.6 \pm 1.0$ & 0.0 & $4.24<0.05$ & $1-2,4$ \\
\hline & & & & & & $\mathrm{BB}=\mathrm{GC}<\mathrm{ST}<\mathrm{C}$ \\
\hline
\end{tabular}

** Group C, Group BB, Group ST, Group GD

water was injected through the same opening; $1 \mathrm{ml}$ of cold water $\left(10^{\circ} \mathrm{C}\right)$ per second was injected through a disposable plastic syringe with 22 gauge needle (0.5 diameter) (Fig. 3).

Each patient's report of tooth sensitivity was scored on visual analog scale (VAS). The VAS consisted of a $10 \mathrm{~mm}$ line where zero is equivalent to 'no pain' and 10 equivalent to 'severe pain' or 'worst imaginable pain'. These values were transformed to number from 0 (nonsensitive) to 10 (extremely hypersensitive). ${ }^{12}$

Evaluation of postcementation sensitivity level: The patient's response to sensitivity was evaluated immediately after 5-minute postcementation, 1-day postcementation, 1-week postcementation at routine recall visits. All individual patient data forms and a summary spreadsheet of the results were thoroughly examined and data was statistically analyzed.

\section{RESULTS}

One-way ANOVA was used for multiple group comparison followed by post hoc Tukey's test for pairwise comparison. The p-value of 0.05 or less was considered for statistical significance. BisBlock and GC Tooth Mousse desensitizer

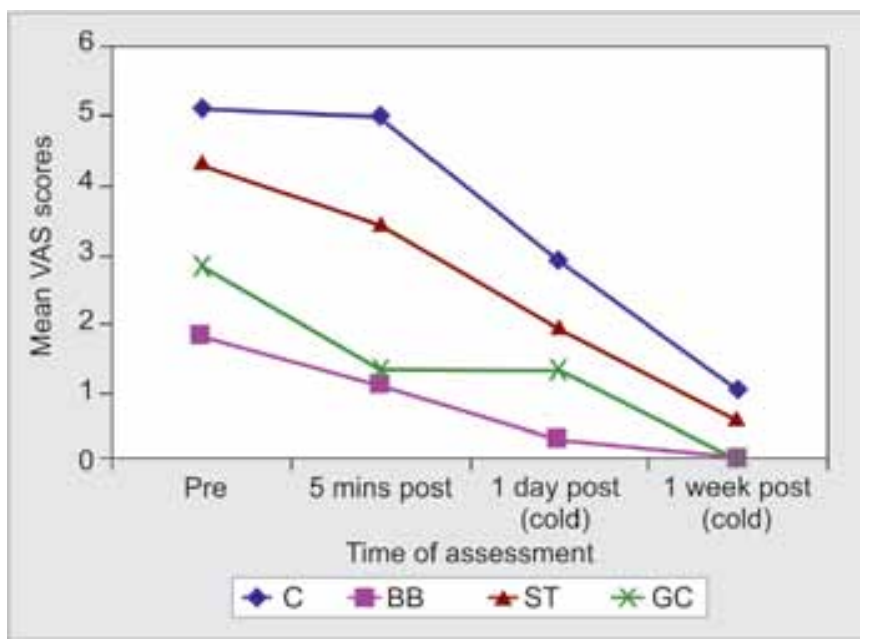

Graph 1: Sensitivity level in different desensitizing agents resulted in statistically significant $(\mathrm{p}<0.01)$ reduction in postcementation sensitivity of glass ionomer cement in comparison to Systemp desensitizer at 5 minutes, 1 week postcementation time interval with no statistical difference was seen between all desensitizer groups at 1 day postcementation. Application of BisBlock and GC Tooth Mousse desensitizer resulted in highly significant $(p<0.01)$ (Table 2) reduction in sensitivity level at the end of 1 week.

No statistically significant difference was seen between the control and Systemp desensitizer in reducing the postcementation sensitivity level at various time intervals. (Table 2 and Graph 1). This observation was different from the result of the other clinical studies ${ }^{14,16}$ that demonstrated significant reduction in sensitivity of prepared teeth after application of Gluma bond (glutaraldehyde-based desensitizer) compared to control group. However, Systemp desensitizer resulted in statistically significant reduction in $(\mathrm{p}<0.01)$ in 5 minutes $(3.4 \pm 1.6), 1$ day $(1.9 \pm 1.7)$, 1 week $(0.6 \pm 1.0)$ postcementation sensitivity level relative to baseline sensitivity level $(4.3 \pm 1.8)$. This finding was similar to other studies ${ }^{18,20}$ that found significant reduction in sensitivity between baseline and postoperative and 1 week response after Gluma bond application.

\section{DISCUSSION}

Patients frequently experience pain or sensitivity in the prepared abutment teeth for some period of time following the placement of the restoration. While reported sensitivity tends to be short term that is several week or less, ${ }^{1,4}$ some cases of prolonged sensitivity upto 1 year or longer have been reported, that eventually required endodontic therapy. ${ }^{4,5}$

Many reasons for sensitivity from the glass ionomer luting agents has been postulated ${ }^{15}$ including:

1. Initial acidity of the cement and prolonged low $\mathrm{pH}$ the glass ionomer cement may exacerbate the dissolution of smear layer and peritubular dentine thereby increases the permeability of the dentine. ${ }^{8}$ 
2. Hydraulic pressure in the dentine tubules produced during cementation may enable the cement to enter dentinal tubules, ${ }^{9,10}$ especially in preparation with minimal remaining dentine thickness with increased dentine permeability.

3. Dehydration of the tooth: if the dentinal canals are dehydrated and wide open it may be possible that there could be some irritation caused by cement.

4. Water solubility during cementation: glass ionomer cement is water soluble immediately after mixing and it is possible that the cement in the margin of the restorations could dissolve out or be significantly disintegrated before initial cement set.

5. Postcementation microleakage associated with in vivo dissolution of luting agents and subsequent bacterial leakage at the margin of restorations.

Furthermore, glass ionomer cement has been reported to generate inflammatory changes in the pulp in the first 48 hours after placement of the material on the dentine. ${ }^{16}$

Although the perceived mechanism of pain transmission and sensitivity within the dentin is subject to speculation, the hydrodynamic mechanism of sensitivity is the most accepted. This theory postulates that the rapid shifts of the fluid in either direction within the dentinal tubules, i.e. toward or away from the pulp, following stimulus application result in activation of sensory nerve ending thereby inducing pain or sensitivity.

The pressures that are generated during cementation of casting are transferred to the fluid in dentin, there is danger that the cement will enter the dentinal tubules before it sets displacing an equal volume of dentinal fluid in pulp. ${ }^{17}$ This could be responsible for the pain that unanesthetized patients experience during cementation of restorations and could plausibly explain the hydrodynamic theory.

It has been demonstrated that dentin permeability (ability of the fluid to shift across dentin) increases as dentin is prepared closer to pulp, hence it should be covered with materials that are biologically compatible with the pulp and will seal the dentin well. ${ }^{11,12}$ Sealing of dentine with bonding agent or desensitizing agent was suggested following tooth preparation and before making impression. ${ }^{18}$ The thin film of these agents decreases the dentin permeability and would also prevent hydraulic fluid movement during impression making and during final luting of the restorations.

In office dentin surface treatment for the management of dentin hypersensitivity include the application of cavity varnishes, calcium hydroxide, various salts (fluoride, calcium, oxalate) that form insoluble precipitate within the dentinal tubules and sealing of dentinal tubules with restorative resin and adhesives (dentin bonding agents). ${ }^{19}$
Desensitizing agents occlude the dentinal tubules at surface (at the tubular orifice) and subsurface (within the dentinal tubules) level preventing the fluid flow and hence reduces the pain sensation by counteracting the hydrodynamic mechanism of dentin hypersensitivity. Dentin bonding agent significantly reduced the pressure transmitted to the pulp chamber and had no effect on the postcementation crown seating. Cherkasski and Wilson also suggested that the preimpression sealing of dentin should be considered for tooth preparation on vital teeth to reduce the pressure transmitted to the pulp chamber during crown cementation. ${ }^{18}$

The effectiveness of various desensitizing agents to block the dentinal tubules and decrease in dentin permeability has been reported in many in vivo and in vitro studies. ${ }^{13-15}$ Clinical efficacy of desensitizing agents in reducing the dentin sensitivity has been reported when applied on vital abutment teeth prepared to receive full coverage or PFM restoration. ${ }^{16-18}$ However, their exact therapeutic action and clinical effectiveness for reducing the postcementation sensitivity level of glass ionomer cement is not clearly defined.

In the present study, three in-office desensitizing agents were used namely, BisBlock dentin desensitizer (Oxalate based), Systemp desensitizer (glutaraldehyde based), and Tooth Mousse desensitizer [Recaldent CPP-ACP (casein phosphopeptide-amorphous calcium phosphate based)] (see Table 1). Respective desensitizing agent was applied immediately after abutment preparation before the final impression was made.

VAS was used for assessment of sensitivity level as it offers the advantage of being a continuous scale, thus providing quantitative measurements that are readily averaged and tested with parametric statistics. ${ }^{28}$ In many clinical studies VAS has been used extensively supporting it as a sensitive tool for measurements of the dentin sensitivity ${ }^{21-26}$ and reliability was reported to be high when repeatedly used with the same individual. ${ }^{27}$

\section{Evaluation of Precementation Sensitivity Level}

In the present study at the time of baseline precementation, lower mean sensitivity VAS score to cold stimulus was seen in desensitizer groups compared to control group. Reduction in perceived sensitivity level score was seen in the following order. BB $(1.8 \pm 1.2)<\mathrm{GC}(2.8 \pm 2.1)<\mathrm{ST}(4.3 \pm 1.8)$ $<\mathrm{C}(5.1 \pm 2.5)$ (see Table 2 and Graph 2). Overall application of all the three desensitizers had considerably reduced the precementation sensitivity of prepared abutment teeth. Difference in the precementation sensitivity level scores among the desensitizer groups may be due to the difference in their chemical composition and mechanism of actions. 
Oxalate containing BisBlock dentin desensitizer application leads to formation of calcium oxalate crystals deep within the tubules that demineralizes the organic and mineral debris of the smear layer and the outermost ring of peritubular dentin and within minutes restructure the demineralized material as calcium oxalate precipitate. ${ }^{32}$

Systemp desensitizer contains polyethylene glycol dimethacrylate and glutaraldehyde in an aqueous solution. Glutaraldehyde is biological fixative that superficially coagulates the plasmatic proteins of dentinal fluid resulting in partial or total occlusion of the dentinal tubules. ${ }^{28,29}$ Thus desensitization, by preventing displacement of liquid across the tubules upon excitation. In the reaction of glutaraldehyde (GDA) with dentine two aldehyde groups present in GDA cross-links with amino groups in the dentin collagen which facilitates protein precipitation inside the dentinal tubules (formation of aldehyde and protein cross linking). ${ }^{28,30}$ Furthermore, it was speculated that glutaraldehyde has distinct in vivo antibacterial effect that inhibits the bacterial growth or invasion through a toothrestoration interface. ${ }^{31}$ It may be expected that desensitizers containing glutaraldehyde might help in reducing the abutment sensitivity associated with microleakage at cervical margins of restoration conceivably by effectively eliminating bacterial contamination.

Tooth Mousse desensitizer contains the active ingredient Recaldent CPP-ACP which desensitizes the surface with its ability to remineralize the hard tissues. ACP is capable of rapid conversion into hydroxyapatite crystals under physiologic oral conditions which can precipitate in the lumen of the dentinal tubules. Tung and others have also shown that calcium phosphate solution at high concentration and at $\mathrm{pH}$ 5 rapidly precipitate ACP that obstruct the dentinal tubules and decreases the dentin permeability by $85 \%$ or more.

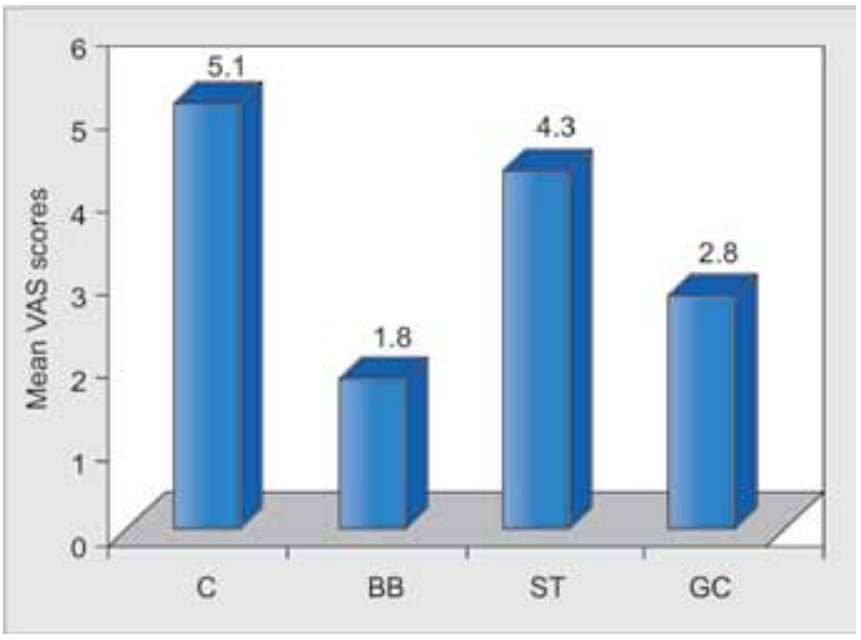

Graph 2: Precementation baseline sensitivity level to cold (one week after desensitizer application before final cementation)
Moreover, when CPP-ACP is applied to tooth surface it binds to biofilms, bacteria hydroxyapatites and surrounding soft tissues localizing the bioavailable calcium and phosphate. Saliva will also enhance the effectiveness of CPP-ACP.

\section{Comparison of Efficacy of Desensitizing Agent}

BisBlock and GC Tooth Mousse desensitizer resulted in statistically significant reduction $(p<0.01)$ in postcementation sensitivity of glass ionomer cement in comparison to Systemp desensitizer at 5 minutes, 1 week postcementation time interval. No statistical difference was seen between all desensitizer groups at 1 day postcementation (see Table 2).

BisBlock and GC desensitizer group (Graph 3) resulted in statistically highly significant $(\mathrm{p}<0.001)$ percentage reduction in sensitivity level at 5 minutes, 1 day, 1 week postcementation relative to baseline sensitivity level in comparison to Systemp desensitizer. In BisBlock desensitizer group reduction in postcementation mean VAS score at different time intervals was 5 minutes $(1.1 \pm 0.7)$, 1 day $(0.30 .7), 1$ week $(0.0 \pm 0.0)$ relative to baseline precementation VAS score $(1.8 \pm 1.2)$.

With the application of oxalate containing desensitizer, greater reduction in mean VAS score from the baseline to various time intervals has been demonstrated in many clinical studies. ${ }^{14,18,25}$

Application of BisBlock and GC Tooth Mousse desensitizer resulted in $100 \%$ reduction in sensitivity level at the end of 1 week relative to baseline sensitivity level compared to Systemp desensitizer (86\% reduction) and control ( $80 \%$ reduction) (see Graph 3). This indicates the efficacy of BisBlock and GC Tooth Mousse desensitizer was more in relieving the postcementation sensitivity of glass ionomer cement at various time intervals in comparison to Systemp desensitizer.

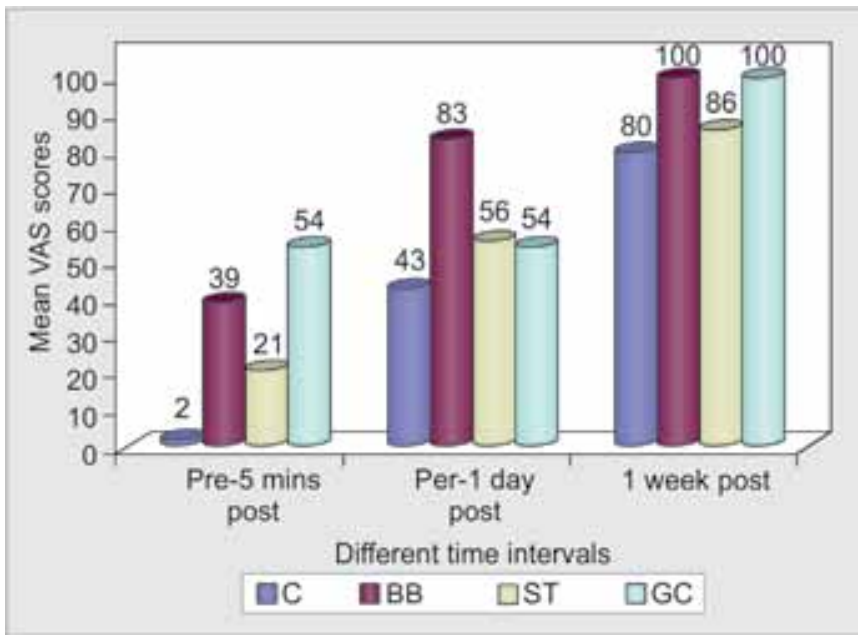

Graph 3: Percentage reduction of sensitivity level at different time intervals compared to baseline precementation in each individual desensitizing agents 


\begin{tabular}{lccccc}
\multicolumn{5}{c}{ Table 3: Comparison of postcementation sensitivity level at different time intervals compared to baseline } \\
precementation in each individual desensitizing agents
\end{tabular}

Dentin surface treatment with soluble acidic oxalate salts has been demonstrated to remove the original smear layer and replace it with an acid resistant layer of calcium oxalate crystals. ${ }^{32}$ This might be the reason application of BisBlock oxalate containing desensitizer on prepared abutment teeth in the present study resulted in greater reduction in postcementation sensitivity of glass ionomer cement by counteracting the initial acids of the cement by acid resistant precipitate that otherwise might have dissolved the pretreatment smear layer on exposed dentin.

Furthermore, the layer of acid resistant crystalline precipitates not only occlude the dentin and reduce dentine permeability also provide a surface rich in calcium and carboxylate group which might be useful for chemical bonding of glass ionomer cement to dentin.

When comparison was made between the sensitivity level of abutment teeth to thermal and bite stimulus no statistical difference was seen in perceived sensitivity score between the three desensitizer groups at 1 day and 1 week postcementation time interval $(\mathrm{p}<0.05)$ (Table 3 ).

Patient's subjective response to thermal stimuli was zero and was not discriminative among all the desensitizer groups. Overall only 2 to 3 subjects in all the groups responded sensitivity to bite stimulus and scored in the range of 0 to 2 on the VAS. The subjective response to the bite stimulus was clinically nonsignificant among all the desensitizer groups.

In the present study in contrast to reduction in VAS scores following cold, hot and bite stimuli, the reduction in VAS scores following the cold stimuli were more discriminative among all the desensitizer groups. The reason for this is not clear but could result from the relatively greater number of dentinal tubules that are potentially stimulated by cold compared to hot and bite stimuli.

It is encouraging that desensitizer's application on the prepared abutment teeth considerably effective in relieving both pre- and postcementation sensitivity for full coverage restoration over the short duration of time. Immediate reduction in postoperative sensitivity relatively in a short time period may be beneficial in terms of patient's comfort.
Nonetheless, multicenter long-term clinical trials should be conducted to confirm the results.

\section{CLINICAL SIGNIFICANCE}

Desensitizer's application on the prepared abutment teeth is considerably effective in relieving both pre- and postcementation sensitivity for full coverage restoration over the short duration of time. Immediate reduction in postoperative sensitivity relatively in a short time period may be beneficial in terms of patient's comfort. Clinical efficacy of desensitizing agents depends on dissolution resistance or solubility level of precipitate or resin in the dentinal tubule.

\section{CONCLUSION}

Efficacy of BisBlock and GC Tooth Mousse desensitizer was more in relieving the postcementation sensitivity of glass ionomer cement at various time intervals in comparison to Systemp desensitizer. A 100\% reduction in sensitivity level was seen with the application of BisBlock and GC Tooth Mousse desensitizer compared to Systemp desensitizer $(86 \%)$ and control $(80 \%)$ at the end of 1 week relative to baseline sensitivity level. In conclusion application of desensitizers was beneficial to reduce the pre- and postcementation abutment sensitivity.

\section{REFERENCES}

1. Brackett WW, Metz JE. Performance of a glass ionomer luting cement over 5 years in a general practice. J Prosthet Dent 1992;67:59-61.

2. Johnson GH, Powell LV, Derouen TA. Evaluation and control of postcementation pulpal sensitivity: zinc phosphate and glass ionomer luting cements. J Am Dent Assoc 1993;124:39-46.

3. Reinhardt JW. Swift EJ, Bolden AJ. A National survey on the use of glass-ionomer cements. Oper Dent 1993;18:56-60.

4. Jokstad A, Mijor IA. Ten year's clinical evaluation of three luting cements. J Dent 1996;24(5):309-315.

5. Jackson CR, Skidmore AE, Rice RT. Pulpal evaluation of teeth restored with fixed prostheses. J Prosthet Dent 1992;67:323-325.

6. Brannstrom M. The effect of dentine desiccation and aspirated odontoblast on the pulp. J Prosthet Dent 1968;20:165-171.

7. Phillips RW, Swartz ML, Lund MS, Moore BK, Vickery J. In vivo disintegration of luting cements. J Am Dent Assoc 1987;114: 489-492. 
8. Smith DC, Ruse ND. Acidity of glass ionomer cements during setting and its relation to pulp sensitivity. J Am Dent Assoc 1986;112:654-657.

9. Reported sensitivity to glass ionomer luting cements. Council on Dental Materials, Instruments and Equipment. J Am Dent Assoc 1984;109:476.

10. Gerzina TM, Hume WR. Movement of glass ionomer cement through human dentine during crown cementation in vitro. J Dent Res 1990;15:934.

11. Brannstrom M. Reducing the risk of sensitivity and pulpal complications after the placement of crowns and fixed partial dentures. Quintessence Int 1996;27:673-678.

12. Lam CW, Wilson PR. Crown cementation and pulpal health. Int Endod J 1999;32:249-256.

13. Felton DA, Bergenholtz G, Kanoy BE. Evaluation of the desensitizing effect of Gluma dentin bond on teeth prepared for complete-coverage restorations. Int J Prosthodont 1991;4: 292-298.

14. Zhang HQ, Chao YL. The effects of desensitizing bonding system for prevention of vital abutment hypersensitivity. Hau Xi Kou Qiang Yi Xue Za Zhi 2005;23(2):130-132.

15. Christensen GJ. Glass ionomer as a luting material. J Am Dent Assoc 1990;120:59-62.

16. Plant CG. Pulpal effects of glass ionomer cement. Int Endod J 1984;17:51-59.

17. Pashley DH. Smear layer physiological considerations. Oper Dent 1984;(suppl 3):13-29.

18. Richardson D, Tao L, Pashley DH. Dentin permeability: effects of crown preparation. Int J Prosthodont 1991;4:219-225.

19. Lam CW, Wilson PR. The effect of dentine surface treatment on pulpward pressure transmission during crown cementation: a laboratory study. Int Dent J 1998;8:196.

20. Holland GR, Narhi MN, Addy M, Gangarosa L, Orchardson R. Guidelines for the design and conduct of clinical trials on dentine hypersensitivity. J Clin Periodontol 1997;24:808-813.

21. Quarnstrom F, Collier N, McDade E, McLean K, Munk AL, Nicholls J. A randomized clinical trial of agents to reduce sensitivity after crown cementation. Gen Dent 1998;71:68-74.

22. Wolfart S, Wegner SM, Kern M. Comparison of using calcium hydroxide or a dentine primer for reducing dentinal pain following crown preparation: a randomized clinical trail with an observation time up to 30 months. J Oral Rehabil 2004;31: 344-350.

23. Kontturi-Narhi V. Narhi M. Testing sensitive dentine in man. Int Endod J 1993;26:4.

24. Yates R, Owens J, Jackson R, Newcombe RG, Addy M. A split-mouth placebo-controlled study to determine the effect of amorphous calcium phosphate in the treatment of dentine hypersensitivity. J Clin Periodontol 1998;25:687-692.

25. Geiger S, Matalon S, Blasbalg J, Tung MS, Eichmiller FC. The clinical effect of amorphous calcium phosphate (ACP) on root surface hypersensitivity. Oper Dent 2003;28(5):496-500.
26. Stewardson DA, Crisp RJ, McHugh S, Lendenmann U, Burke FJ. The effectiveness of Systemp desensitizer in the treatment of dentine hypersensitivity. Prim Dent Care 2004;11(3):71-76.

27. Sim J, Waterfield J. Validity, reliability and responsiveness in the assessment of pain. Physiotherapy Theory and Practice 1997;13:23-37.

28. Dijkman G, Jongebloed WL, de Vries J, Ogaard B, Arends J. Closing of dentinal tubules by glutardialdehyde treatment, a scanning electron microscopy study. Scand J Dent Res 1994;102:144-150.

29. DondiDall'Orologio G, Lone A, Finger WJ. Clinical evaluation of the role of glutaraldehyde in a one-bottle adhesive. Am J Dent 2002;15:330-334.

30. Schupbach P, Lutz F, Finger WJ. Closing of dentinal tubules by Gluma desensitizer. Eur J Oral Sci 1997;105:414-421.

31. Felton DA, Bergenholtz G, Cox CF. Inhibition of bacterial growth under composite restorations following Gluma pretreatment. J Dent Res 1989;68(3):491-495.

32. Pashley DH, Galloway SE. The effects of oxalate treatment on the smear layer of ground surfaces of human dentine. Archs Oral Biol 1985;30(10):731-737.

\section{ABOUT THE AUTHORS}

\section{Naveen Gupta}

Reader, Department of Prosthodontics, Institute of Dental Education and Advanced Studies, Gwalior, Madhya Pradesh, India

\section{Upendra Natha Reddy}

Reader, Department of Conservative Dentistry and Endodontics G Pulla Reddy Dental College and Hospital, Kurnool, Andhra Pradesh India

\section{P Leela Vasundhar}

Professor, Department of Oral and Maxillofacial Surgery, Sri Sai Dental College and Research Institute, Srikakulam, Andhra Pradesh India

\section{K Sita Ramarao}

Professor, Department of Oral and Maxillofacial Surgery, Lenora Institute of Dental Sciences, Rajanmundry, Andhra Pradesh, India

\section{KVV Pratap Varma}

Reader, Department of Orthodontics, Hi-Tech Dental College Bhubaneswar, Odisha, India

\section{Vinod (Corresponding Author)}

Senior Lecturer, Department of Prosthodontics, The Oxford Dental College and Hospital, Bengaluru, Karnataka, India, e-mail: drvinod@ mail.com 